\title{
Packing Dosage Form
}

National Cancer Institute

\section{Source}

National Cancer Institute. Packing Dosage Form. NCI Thesaurus. Code C47887.

A solid composed of a material that contains active and/or inert ingredient(s) which is intended to be placed in a cavity or depression within the body. 